\title{
Carbon Cycle Uncertainty in REgional Carbon Cycle Assessment and Processes (RECCAP)
}

\author{
I. G. Enting ${ }^{1}$, P. J. Rayner ${ }^{1}$, and P. Ciais ${ }^{2}$ \\ ${ }^{1}$ The University of Melbourne, Vic 3010, Australia \\ ${ }^{2}$ Laboratoire des Sciences du Climat et de l'Environnement, CEA-CNRS-UVSQ, Gif sur Yvettte, France
}

Correspondence to: I. G. Enting (ian.g.enting@gmail.com)

Received: 20 December 2011 - Published in Biogeosciences Discuss.: 15 February 2012

Revised: 5 June 2012 - Accepted: 21 June 2012 - Published: 2 August 2012

\begin{abstract}
Characterisation of estimates of regional carbon budgets and processes is inherently a statistical task. In full form this means that almost all quantities used or produced are realizations or instances of probability distributions. We usually compress the description of these distributions by using some kind of location parameter (e.g. the mean) and some measure of spread or uncertainty (e.g. the standard deviation). Characterising and calculating these uncertainties, and their structure in space and time, is as important as the location parameter, but uncertainties are both hard to calculate and hard to interpret. In this paper we describe the various classes of uncertainty that arise in a process like RECCAP and describe how they interact in formal estimation procedures. We also point out the impact these uncertainties will have on the various RECCAP synthesis activities.
\end{abstract}

\section{Introduction}

The REgional Carbon Cycle Assessment and Processes (RECCAP) activity (Canadell et al., 2011) is an international activity, designed to explicitly consider the spatial dimension in analyses of the behaviour of the carbon cycle.

The present paper (as part of a series of RECCAP papers) considers various aspects of the RECCAP studies of carbon fluxes with the aim of reviewing the uncertainties. In particular we consider the extent of cross-information between the various RECCAP components, with analyses of different data streams serving to confirm each other, thus reducing the overall uncertainty, or disagreeing, indicating that some aspect of uncertainty has been underestimated. We confine our attention to surface-atmosphere carbon fluxes and some horizontal carbon fluxes, and only consider other RECCAP products such as inventories to the extent that the RECCAP analysis specifically relates to them.

In this overview, we propose that:

- in general terms, we consider the RECCAP activity as being that of statistical estimation, i.e. constructing statistical estimates of carbon fluxes and related quantities;

- as a specific choice, we consider the temporal aspects by using a decomposition similar to that described by Cleveland et al. (1983) regarding the fluxes as a combination of long-term trend, slowly-varying cycle and additional "irregular" variation. We show how the RECCAP categories map onto this decomposition.

Our discussion is in the spirit of Raupach et al. (2005) who wrote that "An essential commonality is that for all model-data synthesis problems, both nonsequential and sequential, data uncertainties are as important as data values themselves and have a comparable role in determining the outcome". The ideal is that synthesis of RECCAP products is based as far as possible on traceable statistical analysis. (We are using the term "synthesis" as used by Raupach et al. (2005) and in RECCAP, and specifically say "synthesis inversion" for the concept described by Fung et al. (1991).) In extending the Raupach et al. (2005) discussion, we have focused on those aspects that are most relevant to RECCAP, but the considerations are, of course, more broadly applicable in Earth system science.

We motivate what follows with a simple demonstration of the interaction of different kinds of uncertainty on different classes of data. Figure 1 gives a schematic of the relation between the impact of integrated and pointwise observations. 


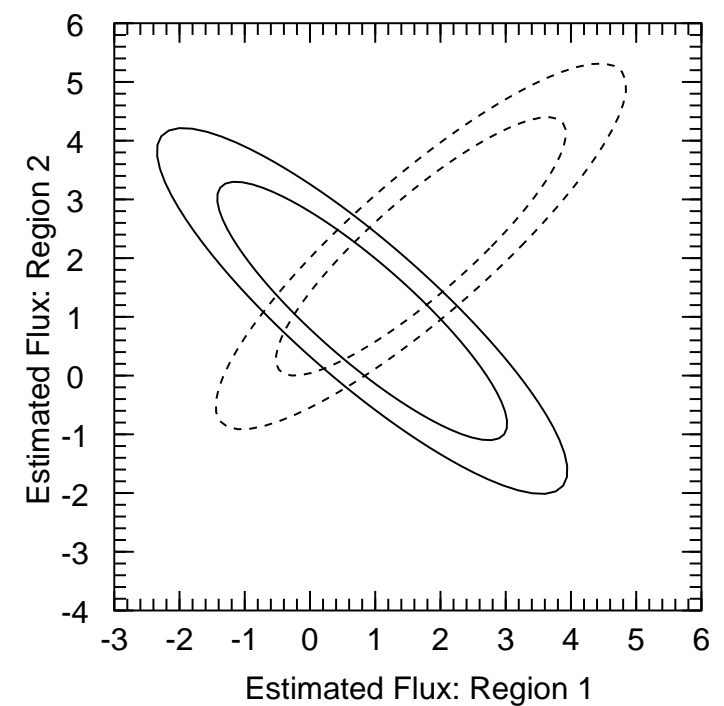

Fig. 1. Schematic of relation between top-down (solid ellipses) and bottom-up (dashed ellipses) estimates, for an idealised case with two flux components.

Integrated observations (such as atmospheric concentration) integrate over many flux components from multiple processes and multiple regions. The weighted sum of these components is hence well-constrained leading to negative correlations among individual flux estimates. On the other hand, pointwise observations such as process studies are often beset by common measurement or methodological problems so that an error made at one point will likely be made at another, i.e. errors are positively correlated.

Figure 1 shows that the combination of these two pieces of information (the intersection of the two ellipses) depends critically on these different correlation structures, thus it is important that we define them. The challenge for analysing the uncertainties inherent in RECCAP is that many of these uncertainties, particularly those associated with "model error", are poorly quantified.

The outline of the remainder of this paper is as follows. Section 2 notes the size of the full problem and the need to work with restricted projections of a full description of uncertainty, even in the case of multi-variate Gaussian distributions. Some mathematical implications are emphasised. Section 3 considers various aspects of modelling uncertainties in terms of four classes - models, data products, inventories and inversions - refining the top-down/bottom-up classification and reflecting the considerations raised by Raupach et al. (2005). Section 4 describes a three-way decomposition by time, process and region. Section 5 describes the implications of our approach when analysing the global carbon budget and its regional decomposition, and Sect. 5.2 reviews the various RECCAP "global products" in these terms. Section 5.3 applies the discussion of the earlier sections to considering the regional analysis, which is the raison d'être of
RECCAP. It reviews the discussion of uncertainty in the various RECCAP regional analyses and explores how this affects the ability to achieve a global synthesis with quantified uncertainty. Our concluding section aims to set the scene for consistent uncertainty analysis in high-level RECCAP syntheses. As noted above, although our discussion is focused on the RECCAP activity, our conclusions are more broadly applicable. Similarly, our examples draw mainly on carbon cycle studies rather than broader areas of science, but of course many of the studies that we use as examples draw on a broad science base.

In this paper our aim is to explore the limits of formal statistical analysis, but we note some broader issues beyond this scope. The First State of the Carbon Cycle Report (SOCCR) (CCSP, 2007) notes that "rarely, even within a sector or discipline, are the statistical pre-requisites of meta-analysis met by the diverse studies of carbon cycle elements". In such circumstances, expert judgments can be applied, and the focus needs to be on consistent communication of the assessments. In the IPCC reports, uncertainties presented in formal terms are qualified with a descriptor of how reliable they are thought to be. Other assessments such as the SOCCR study have adopted similar approaches. The IPCC usage tended to differ between the working groups - indeed Ha-Duong et al. (2007) argued that this was desirable given the differences in the fields. However, this inconsistency in terminology was recently criticised by the review of IPCC procedures (Committee to Review the IPCC, 2010).

\section{Characterising uncertainty}

\subsection{The exabyte covariance matrix}

A statistical characterisation of flux estimates requires both a measure of "location" (e.g. mean, mode or median) and a measure of the spread (e.g. percentile ranges or standard deviation) expressing the uncertainty in the measure of "location". Except for special distributions that can be fully characterised by two such parameters, additional moments of these distributions will need to be specified for a full description.

A minimal description of the uncertainty in a set of estimates such as RECCAP fluxes is given by the covariance. However, we are immediately confronted by the size of the problem. For 1 degree by 1 degree resolution over 20 years with 52 weeks and 5 processes active at each point, we have $\approx 3 \times 10^{8}$ flux components to be estimated. The size of the covariance matrix, $\mathbf{C}$, is the square of this, and even subsets of this matrix need to be carried to relatively high precision for numerically stable manipulations. These are only illustrative numbers since any discretization is a truncation relative to the continuous flux and concentration fields, with processes such as growth and disturbance occurring at scales of metres or less. Even within RECCAP, some studies have 
spatial resolution of one kilometre and/or hourly time resolution. Where such fine scales are needed for models, inventories or data products, the uncertainty must be considered at the same scales.

The fact that the analysis will never be working with the full matrix $\mathbf{C}$ makes it important to characterise the nature of truncations and projections. For multi-variate Gaussian distributions, two different problems arise whenever we consider a projection of $\mathbf{C}$. These can be classed as truncation and ambiguity. Both pose problems for the calculation and interpretation of budgets, but, in both cases, proper treatment of the statistics of the problem can avoid trouble and generate information.

\subsection{Truncation}

The general relation for building up the inverse covariance matrix, $\mathbf{X}=\mathbf{C}^{-1}$, as information is combined, is expressed as successive instances of

$\mathbf{X} \leftarrow \mathbf{X}^{\prime}=\mathbf{X}+\mathbf{G}^{\top} \mathbf{W G}$

where $\mathbf{G}$ is a model operator that maps the fluxes onto a set of observations whose covariance is $\mathbf{R}$ with the inverse $\mathbf{W}=$ $\mathbf{R}^{-1}$.

Some of the issues of truncations and projections can be illustrated by considering $\mathbf{X}$ transformed so as to be partitioned into sets 1 and 2 of "resolved" and "unresolved" fluxes - these could, for example, be "low-resolution" and "high resolution" in space and or time. Rewriting (1) in block matrix form gives:

$$
\begin{aligned}
& {\left[\begin{array}{ll}
\mathbf{X}_{11} & \mathbf{X}_{12} \\
\mathbf{X}_{21} & \mathbf{X}_{22}
\end{array}\right] \leftarrow\left[\begin{array}{ll}
\mathbf{X}_{11}^{\prime} & \mathbf{X}_{12}^{\prime} \\
\mathbf{X}_{21}^{\prime} & \mathbf{X}_{22}^{\prime}
\end{array}\right]} \\
& =\left[\begin{array}{ll}
\mathbf{X}_{11} & \mathbf{X}_{12} \\
\mathbf{X}_{21} & \mathbf{X}_{22}
\end{array}\right]+\left[\mathbf{G}_{1}^{\top} \mathbf{G}_{2}^{\top}\right] \mathbf{W}\left[\begin{array}{l}
\mathbf{G}_{1} \\
\mathbf{G}_{2}
\end{array}\right]
\end{aligned}
$$

with a corresponding block decomposition of $\mathbf{C}$.

There are several cases depending on the content of $\mathbf{G}$ and $\mathbf{X}$

$\mathbf{G}_{1}=0$. (or $\mathbf{G}_{2}=0$ ) Here, the observations inform only one of the two resolutions, but information may be passed to the other by preexisting correlations $\left(\mathbf{X}_{12} \neq 0\right)$.

$\mathbf{C}_{22} \approx 0$. Here, although observations inform both subspaces, we assume near perfect knowledge of the high-resolution space. This approach was used, for example, by Zupanski et al. (2007) who assumed knowledge of high-frequency variations in flux and used continuous atmospheric concentration observations to inform more slowly varying components. Trampert and Sneider (1996) and Kaminski et al. (2001) showed that, if the confidence implied by $\mathbf{C}_{22} \approx 0$ was ill-founded, the low-resolution estimates would suffer a biased inference. The error resulting from such truncation is termed a "truncation" or "aggregation" error.

We can, however, ignore $\mathbf{X}_{22}$ when updating $\mathbf{C}_{11}$, i.e. pretend the problem is carried out only in the low-resolution subspace.
General case. We must consider both resolutions together; hence, we must construct then invert $\mathbf{X}$ and only then take the relevant submatrix for subspace 1 .

Issues of de facto truncation are particularly significant in ill-conditioned inverse problems where some form of regularisation is needed. We note three different cases that tend to shade into each other, but for which the results really refer to somewhat different things:

i. The information that is lost or degraded from the inversion is supplied by other observations - this is what is envisaged in Fig. 1. Prior estimates can play this role in Bayesian inversions.

ii. The inverse problem is replaced by a different (but related) problem by truncating the solution space. This was pioneered by Backus and Gilbert (1968) in seismology.

iii. Extra constraints are added to supplement the observations. These constraints are often motivated by external ideas of reasonable ranges. The parameters that define these ranges contribute information and hence reduce uncertainty. Such approaches return a biased estimate but with a reduced error compared to their unconstrained counterparts. This approach comes in many variants: e.g. ridge regression, shrinkage estimators.

These issues apply far more widely than just RECCAP and the carbon cycle. However, the evolution of the field has seen carbon cycle studies draw heavily on experience from other areas of science, with relatively little sign of practices in the analysis of the carbon cycle influencing wider practice.

\subsection{Ambiguity}

When a total carbon flux is decomposed into contributions from different processes, ambiguity can arise from imprecision in the definitions, with a given flux component attributed to more than one process, or to none. We will use "ambiguity" here in this limited sense and exclude other forms of imprecision such as the failure to distinguish between flux vs. storage budgets and/or $\mathrm{CO}_{2}$ vs. carbon budgets (Enting, 2002, Sect. 14.1). We also exclude "equifinality", i.e. illconditioning of calibration. This is noted in Sect. 3.2.

The problem of ambiguity is illustrated by the case of seasonal savanna burning. A common disaggregation for terrestrial fluxes may include an undisturbed seasonal cycle and a biomass burning contribution. In savanna ecosystems the undisturbed seasonal cycle will include the decomposition of annual grasses at the end of the dry season. This is also a common time for savanna fires. If these two components are independently estimated, such as by a terrestrial model with no burning processes and satellite estimates of burned area, a given carbon atom may be classified as passing from the surface to the atmosphere twice. A solution is to build a single model that treats both processes and conserves mass (e.g. 
Van Der Werf et al., 2006), but this is not always possible or desirable. An alternative is to explicitly budget the "difference" processes. Even if these are poorly known, large proportional uncertainties in a small component will give only small contributions to absolute uncertainty, although it must be realised that there can be a number of such ambiguities. An equivalent approach acknowledges the coupling of the two estimates by including negative covariances into $\mathbf{C}$ and partitioning the prior estimates accordingly. Observations that project onto only one of the covarying components will also help constrain the other, and we can choose to project onto sums of the troublesome components if we wish to avoid the ambiguity altogether.

An important point to note is that while $\mathbf{C}$ can be extended to describe linear combinations of fluxes, the inverse $\mathbf{X}=$ $\mathbf{C}^{-1}$ only exists for a set of linearly independent fluxes since otherwise $\mathbf{C}$ is singular. In the normal Bayesian approach, the prior covariance usually provides a linearly independent basis, but this may not be the case if ambiguous components are included.

\section{Filling in the matrix}

\subsection{Principles}

The uncertainties in RECCAP data sets are considered in terms of four classes, each with somewhat different statistical characteristics, building on the discussion by Raupach et al. (2005). We characterise these types of data set as "models", "data products", "inventories" and "inversions". This order of presentation reflects some of the ambiguities and overlaps between the classes. We begin with "models" because almost all cases of the other types of data set actually involve some sort of model. There is, of course, quite direct use of models in data products. As noted below, aspects of inventory construction are comparable to the development of "data products". Finally, inversions not only have a model (of atmospheric and/or ocean carbon transport) as a key component, but also, if Bayesian techniques are used, the inversions will bring in, as priors, other classes of estimate, each with their own model and classes of error.

Raupach et al. (2005) noted that their discussion was "largely omitting questions of spatial and temporal error structure". We have been able to add relatively little in quantitative terms, but in various sections below, we note studies that can contribute to this essential aspect of carbon cycle uncertainty.

\subsection{Models}

For the purposes of this discussion, we classify model error as structural error, parameter error, forcing error and representation error, noting that there can be some overlapping of the categories. To the extent that they are distinct, these types of error will be cumulative, although not necessarily strictly additive. Intercomparison studies, where multiple models are run with various sets of standard conditions, provide a way of identifying the relative importance of these types of error. Again, these considerations apply across wide areas of Earth system science, but, where appropriate, we draw our examples from carbon cycle studies.

Structural error. Structural error in models occurs when models misrepresent the functional forms of the relations between inputs and observable quantities. It usually requires a calibration exercise to identify it (since we must exclude parameter error described below) or, in rare cases, one can perform a perfect experiment in which the inputs are exactly known. Model intercomparisons can explore the significance of different modelling choices and may show intermodel spreads comparable to the differences between model means and observations (Doney et al., 2004). However, as noted by Knutti et al. (2010) in the context of climate modelling, intercomparisons are not designed to yield formal error estimates.

Representation error. This arises from the mismatch between what a model represents (e.g. grid cells) and what gets observed (e.g. local values). As such it could be considered as a special case of "structural error". In some cases there is an ambiguity as to whether such error should be regarded as a model error (failure to represent detailed behaviour) or observational error (failure of the observational data to capture the scales of the model) (Enting, 2002, Sect. 5.4.1).

Parameter error. Even when model structure is correct, there is usually insufficient information from ab initio reasoning or observations to specify precisely the model parameters. The common argument that we cannot undertake a formal calibration exercise with insufficient information hides rather than circumvents this problem. Parameter sensitivities for specific terrestrial carbon models have been studied by Mitchell et al. (2009) for Biome-BGC and by Zaehle et al. (2005) for LPJ-DVGM. Calibration uncertainty is more amenable to statistical analysis - note in particular the Optimisation InterComparison (OptIC) for comparison of parameter estimation methods in terrestrial biogeochemical models (Trudinger et al., 2008). An extreme case of parameter uncertainty is what is known as "equifinality" where multiple solutions of the calibration calculation are possible because the calibration is under-determined.

Forcing error. Zhao et al. (2011) have investigated the effect of uncertainty in meteorological forcing of fluxes from the ORCHIDEE terrestrial carbon model, comparing results with observed meteorology at tower sites and four different sets of gridded meteorological fields. Jung et al. (2007) compared three terrestrial biosphere models, one run with two different sets of meteorological forcing. They found that differences in forcing were particularly important for interannual variations of GPP. Other aspects of the model behaviour were more sensitive to structural differences such as the treatment of the nitrogen cycle.

The RECCAP activity involves two types of forward models, ocean carbon models and terrestrial carbon models, and intercomparisons have been made for each. Orr et al. (2001) described the OCMIP (ocean carbon) intercomparison, and Doney et al. (2004) analysed OCMIP-2, suggesting that once models were selected on the basis of more realistic physics, 
the real uncertainty in projections of biogeochemical fields would be less than the between model spread. Sitch et al. (2008) have compared terrestrial models, and the earlier Potsdam NPP intercomparison is described by Cramer et al. (1999), with a subsequent study describing the models' responses to climate change (Cramer et al., 2001). All studies showed large differences between models, even when as many inputs as possible were standardized.

Issues of combining results from multiple models have been particularly important for climate modelling. An IPCC expert group has prepared a set of guidelines for use of multiple models (Knutti et al., 2010).

\subsection{Data products}

For RECCAP, the main types of "data product" come from remotely sensed data (often calibrated by ground truth). Such data require a model representation to interpret the raw data (radiances at various frequencies) as properties of the Earth system. Raupach et al. (2005) give tables of indicative properties of error covariance in such observing systems, but, apart from noting the importance, they say little about the spatial and temporal covariance.

Beer et al. (2010) used, among other techniques, various spatially distributed fields, including the remotely sensed fraction of absorbed photosynthetically active radiation (FAPAR), to model GPP with their model calibrated at fluxnet sites.

Beer et al. (2010) shows another important characteristic of these data products: the observations are rarely of the exact quantity needed by a study such as RECCAP. There is a more or less simple model relating the observations and the RECCAP-relevant field, and so the "model errors" described above also pertain to these products.

An important type of data product for regional carbon studies is obtained by up-scaling of FLUXNET data. Jung et al. (2011) used a machine learning approach to up-scale FLUXNET data to $0.5^{\circ}$ by $0.5^{\circ}$ global coverage at monthly resolution using remotely-sensed data for meteorology and land use. They had previously undertaken a "synthetic data" study (Jung et al., 2009) in order to assess various machine learning approaches to such upscaling of GPP. They suggested relatively small uncertainties in their GPP (about $6 \%$ ).

A disappointing but unsurprising result from the Jung et al. (2011) study was that predictive capability was relatively poor for Net Ecosystem Exchange.

In considering spatially and temporally ranging data sets and data products, we need to consider the separate roles of variability and uncertainty. These are distinct concepts, although variability will contribute to uncertainty when estimates are based on sub-sampling a quantity with spatial or temporal variability. Enting (2008) has used the cases of stationary temporal variation to illustrate how different combinations of signal variability and correlation in the noise affect the uncertainty in optimal estimation for various cases of

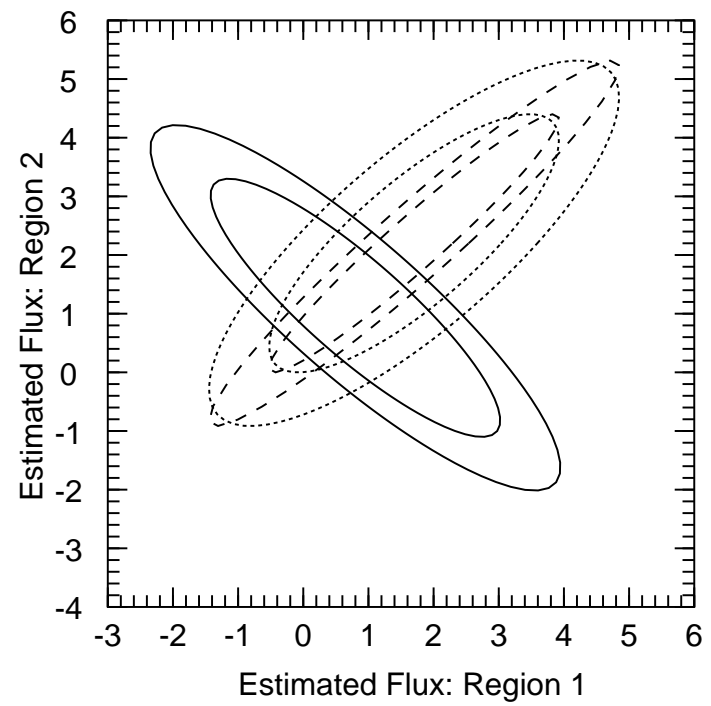

Fig. 2. Schematic of relations between top-down and bottom-up estimates for two idealised cases of two flux components which differ greatly in the quality of bottom-up information.

subsampling (i.e. spectral truncation). For spatial variability and uncertainty, the situation is more complicated, because two-dimensional variation and correlation need to be considered and neither of these will necessarily have a stationary distribution.

\subsection{Inventories}

We use the term here in its literal sense of constructing a total by counting. The task will often be divided, e.g. different uses for fossil fuels, or may involve sampling such as biomass derived from detailed plot studies. Furthermore, the measured and desired quantities are rarely the same and so some kind of model frequently intervenes (e.g. allometric equations (e.g. Wolf et al., 2010) or the Kaya identity (e.g. Rayner, 2010)).

Inventories are often used as prior estimates in inversions, and they often provide detail at much smaller scales than can be informed by the atmosphere. Heimann et al. (2004) noted that "the impressive regional details....are to a large extent provided by the a priori flux fields" - it follows that all the uncertainties in the fine-resolution detail of the posterior flux comes from the priors.

Figure 2 gives a schematic of this. Two different cases of bottom-up information are shown, both with the same methodological uncertainty, but one (dotted ellipses) having much larger inter-case uncertainty than the other (dashed ellipses). This illustration suggests that in such cases, the topdown constraint does little to help the improved bottom-up information reduce the overall uncertainty. Note also that many inventories are defined only at integrated scales, such 
as national UNFCCC emission estimates or crop yields aggregated to administrative regions.

Calculation of uncertainties in inventories is, in principle, simple if the inventory is calculated by direct sum. Calculation of the covariance structure of inventory-based estimates is much harder, since problems like omitted categories are systematic and persistent.

\subsection{Inversions}

Inversions represent cases of indirect inference where the direction of inference is in the opposite direction to real-world causality. Consequently, the dissipative nature of most biophysical systems means that such inverse problems will be ill-conditioned: highly sensitive to both model error and data error.

The "classic" atmospheric $\mathrm{CO}_{2}$ inversion problem of deducing surface fluxes from concentration data was described by Enting (2002). The study by Chevallier et al. (2010) illustrates many of the refinements that have been developed over the last decade. Gloor et al. (2003) described a synthesis inversion approach to using interior ocean data to estimate air-sea fluxes. There have also been joint atmosphere-ocean carbon inversions (Jacobson et al., 2007a,b).

Given that concentration changes represent the combined effects of transport and net sources, inversions use the concentration data along with modelled transport in order to estimate net sources, so that uncertainty arises from both the concentration data and the modelled transport. The Bayesian synthesis inversion propagates observational error (Enting et al., 1995). Notionally, this type of inversion calculation can also propagate model error (Tarantola, 2005, see Eq. 1.101), but the very different statistical characteristics of "model error" limit the extent to which this can be done in practice.

The issues of model error discussed above recur in the role of model error in inversions. The TransCom intercomparison (Gurney et al., 2002) contributes to understanding of atmospheric transport uncertainty, both through collective studies and through targeted investigations of specific cases. As with other intercomparisons (Knutti et al., 2010), this has not translated into a generic quantitative prescription for assessing these errors. Indeed, models can share a systematic bias (Stephens et al., 2007). Estimation of the error characteristics of atmospheric models is possible in applications data assimilation for numerical weather prediction (NWP). This is because of the large amounts of data and the repeated ability to compare the forecast (and associated estimates of uncertainty) to the next set of observations (Dee and de Silva, 1999, for example).

For global-scale $\mathrm{CO}_{2}$ inversions, with less data available, common practice has been to estimate the observational error from the precision and variability found in the measurement program. Alternatively, Michalak et al. (2005) has shown that if groups of measurements can be assumed to have a fixed structure of variance, then scaling factors for this variance can be an additional parameter to be estimated by maximum likelihood. Gourdji (2011) has noted that the same approach could, in principle, be applied to estimating variances of prior fluxes in Bayesian inversions. In mesoscale inversions, with more data available, the inverse problem is closer to data assimilation in NWP and combined uncertainties, including transport uncertainty, can be estimated (e.g. Lauvaux et al., 2009).

Many atmospheric $\mathrm{CO}_{2}$ inversions have considered only atmospheric transport of $\mathrm{CO}_{2}$ and neglected other lateral transports of carbon. The main cases of such transports are river carbon (organic and inorganic), trade (food and fibre), and atmospheric transport of reduced carbon (mainly $\mathrm{CO}$ and $\mathrm{CH}_{4}$ ). Neglect of such lateral transport can cause a number of problems:

- a bias in the priors and/or pre-subtracted fields;

- neglect of particular fluxes - omission of the $\mathrm{CO}_{2}$ source from oxidation of $\mathrm{CO}$ in the free atmosphere is particularly problematic since error cannot be simply corrected by local repartitioning of estimated surface fluxes;

- misinterpretation of results - for example an agricultural region may appear to the atmosphere as a significant sink while transport of the resulting crop may imply no net storage.

The last of these problems represents a bias that can be corrected by simple post-processing of the results, but the first two require a model-dependent correction that will usually not be available.

The various lateral transports have been discussed: reduced carbon (Enting and Mansbridge, 1991; Suntharalingam et al., 2005; Folberth et al., 2005), trade (Ciais et al., 2007, 2008) and rivers (Ciais et al., 2008; Sarmiento and Sundquist, 1992). The neglect of such lateral transport in inversions should be treated as a bias or "offset" to be corrected, not just as an added uncertainty as is done for the "truncation bias" (Kaminski et al., 2001). There is, of course, a need to address the uncertainty in the offset correction.

Commonly, $\mathrm{CO}_{2}$ inversions adopt a Bayesian approach and incorporate various types of "bottom-up" information. In a Bayesian mode, the $\mathrm{CO}_{2}$ inversion is performing the synthesis shown schematically in Fig. 1. This is a very powerful approach but, for the purposes of RECCAP, is subject to an important caveat that such estimates are not independent of the various other components of the RECCAP analysis. Atmospheric inversions are an important component of RECCAP (Canadell et al., 2011), and the results will be reported as part of the present special issue.

A new "variable selection" approach to $\mathrm{CO}_{2}$ inversions has been described by Gourdji (2011) - (see also Huntzinger et al., 2011). A geostatistical inversion has its "geostatistical trend" term supplemented by a small number of auxiliary 

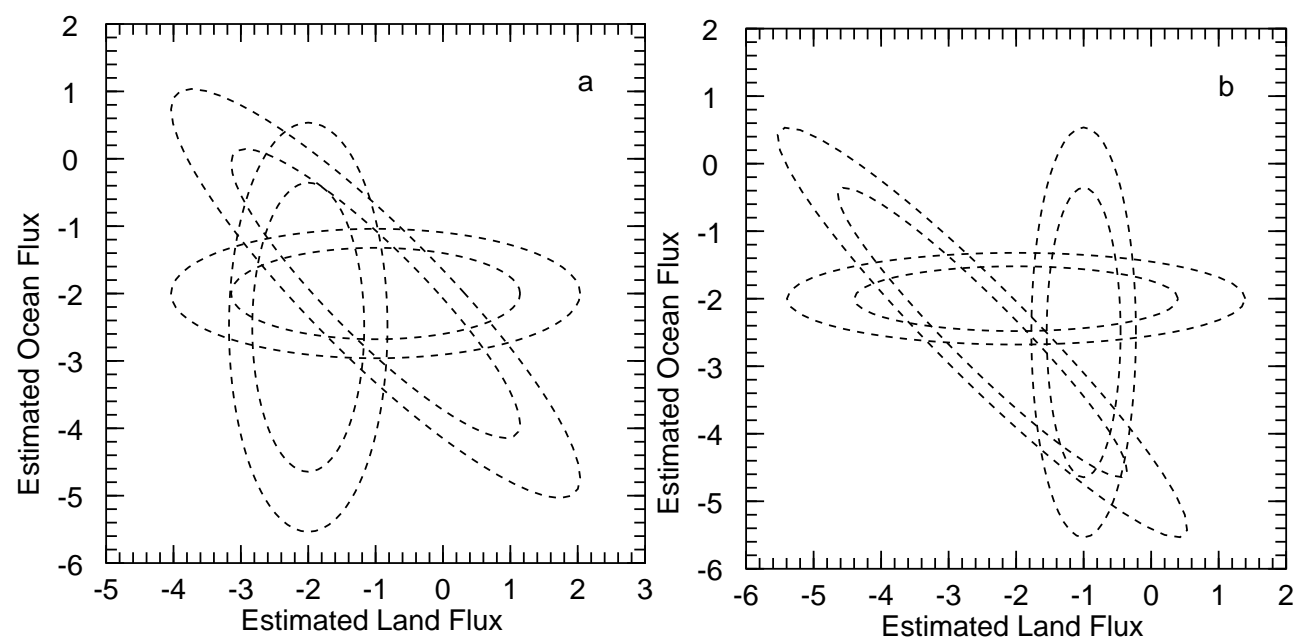

Fig. 3. Schematic of two different possibilities for relations between multiple estimates of carbon budget. (a): Various classes of estimate give consistent views that can be combined to refine the overall budget. (b): Various classes of estimate do not give consistent views and imply the need to estimate (and seek to identify) a residual process.

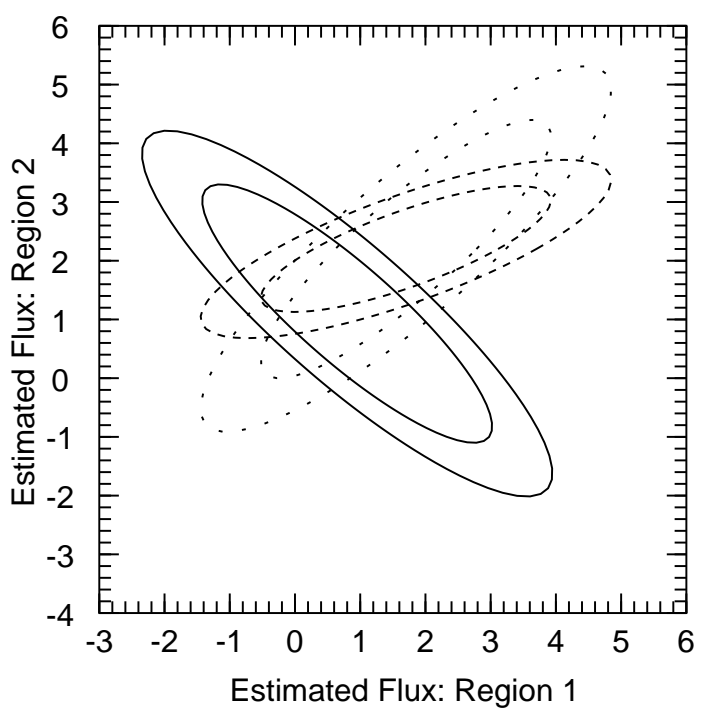

Fig. 4. Schematic of relations between top-down and bottom-up estimates for idealised case of two flux components which differ greatly in the quality of bottom-up information.

space-time distributions chosen from data sets that are expected to be relevant to $\mathrm{CO}_{2}$ flux. A stepwise choice of which set of variables are included is made on the basis of statistical tests, with the process terminating when none of the remaining candidate variables give sufficient improvement to the fit. This type of approach may provide a basis for using Bayesian inversion with multiple models of potential fluxes (or transport).

\section{Decompositions of fluxes}

\subsection{Temporal decompositions}

As noted in the introduction, we follow Cleveland et al. (1983) in representing the fluxes as a combination of longterm trend, slowly-varying cycle and additional "irregular" variation. This general separation into three temporal components represents a form of spectral filtering, although the appropriateness of the specific robust non-linear filters used by Cleveland et al. (1983) will depend on the data set in question.

As a point of clarification, it is important to distinguish between the various meanings of the term "trend". In much of the RECCAP analysis, the term "trend" refers to the rate of change. For Cleveland et al. (1983) "the trend" refers to a slowly varying function - we use the term "trend function" to distinguish this usage. In geostatistical analysis, "the trend" refers to an underlying function that constrains the solution (Michalak et al., 2004; Gourdji, 2011, for example). We use the term "geostatistics trend" for this case.

Overall, the decomposition encompasses the aims and capacity of the RECCAP study, while providing precise definitions and the capacity for more detailed descriptions in future studies. At present, for some components of RECCAP (e.g. ocean inversions) only long-term means are available.

On expressing the RECCAP contributions in terms of this decomposition into temporal components:

- the RECCAP "mean" becomes a particular value of the trend function - it needs to be referenced to a particular time, and there must be a specification of the timeaveraging that is used in producing the trend function; 
- the RECCAP "trend", i.e. the rate of change is thus the derivative of the trend function, again requiring a specification of the reference time and the time-averaging;

- the time averaged characteristics of cycle represent the value of the "cycle" function, again at a particular time and with a particular smoothing - it can be characterised in terms of slowly varying amplitude and phase for each harmonic;

- changes of cycles can be expressed as rate of change of the amplitudes and phases;

- the irregular component is, of course, the most complicated, but summary statistics, e.g. the root-mean-square value, can help characterise this component and, potentially, any sustained changes in its behaviour.

For many components of RECCAP, the higher frequency data will not be available.

Uncertainties in each of the components come from:

- distortion of the signal, due to the estimation procedure differing from the formal requirements (e.g. when data records are too short too support the degree of smoothing applied for other RECCAP components);

- contamination of one component by another due to the estimation procedure differing from the formal requirements;

- uncertainty in original data at frequencies passed by the decomposition procedure. Often this is estimated from residuals by assuming a white noise structure. Any such assumption needs to be justified.

In spectral terms it would be desirable to have the frequencies that are included in the "trend function" well separated from the dominant frequencies of the interannual variability which have a significant ENSO contribution. However, it will often be necessary to compromise due to the limited length of series, e.g. use of 5-yr running mean in Southern Ocean studies (B. Tilbrook, personal communication, 2011).

Each of the separated components can be considered as an example of "truncated solutions" as discussed in Sect. 2.2; the discussion of that section gives the criteria for whether or not the uncertainties for a particular temporal component can be treated in isolation from the other components (e.g. Thompson et al., 2010).

\subsection{Process decompositions}

Table 1 shows a hierarchical decomposition of carbon-cycle processes acting at a point. Different combinations of fluxes are captured by various observational and modelling approaches. Such a complex description demands care to either avoid or characterize ambiguity, but it does not necessarily follow that we should therefore seek a simpler description.
Table 1. Hierarchical decomposition of carbon cycle processes and fluxes acting at terrestrial ecosystem locations. Terrestrial sites can also have emissions from human and geological processes. Various observational and modelling approaches capture different groups of fluxes. Some of these carbon exchanges, particularly respiration and disturbance, need to be further partitioned between $\mathrm{CO}_{2}$ and various forms of reduced carbon. The role of climate change in various forms of disturbance is an additional ambiguity.

\begin{tabular}{lll}
\hline GPP & \\
\hline Respiration & Autotrophic & \\
& Heterotrophic & \\
Disturbance & Storm damage & \\
& Pests & direct \\
& Fire & \\
& Fire & \\
& Other effects of climate change \\
& & \\
& Biofuel harvest & \\
& Crop harvest & \\
& Manure addition etc (Import) & \\
& Export by rivers & \\
& Timber harvest & \\
\hline
\end{tabular}

Many of these processes are linked by the dynamics of carbon pools, and it remains a topic of much debate whether we should build these couplings (via some kind of model) into the inverse mechanism or not. Such an approach reduces the dimensionality of the problem but may also introduce incorrect dynamics. It is possible to include the model state in the estimation so that it, along with model parameters and forcing, can be affected by observations. This is the so-called weak constraint formalism in which the model need not evolve exactly according to its prescribed dynamics. This is particularly valuable when the forms of the dynamical equations are themselves uncertain. Wang et al. (2009) pointed out that the Kalman Filter naturally incorporates a weak dynamical constraint. Another approach, the explicit consideration of residual fluxes, is considered below.

\subsection{Spatial decompositions}

The spatial decomposition of the carbon cycle is the essence of the RECCAP activity. Compared to the time-domain, there is much less in the way of well-established statistical techniques. Furthermore, an assumption of statistical stationarity must be restricted to the smaller scales. For the carbon cycle, spatial differences occur in many different contexts. Often, the interest in spatial information is as a proxy for process. Natural fluxes reflect the Earth's biogeochemical regions: biomes and ocean provinces. Political divisions are reflected in the patterns of human emissions, and the extent to which data about these emissions (and other carbon cycle data) are collected. Inversions are generally spatially-limited, 
only able to provide estimates of a limited number of modes. Furthermore, these modes are determined by the data and cannot be arbitrarily assigned by the investigator (Wunsch and Minster, 1982).

The various types of spatial decomposition are generally not well matched, beyond the obvious land vs. ocean partition. The need for re-mapping between mis-matched spatial decompositions becomes an additional source of bias and ambiguity, comparable to that associated with process ambiguity. Again, an appropriate approach is explicit inclusion of mis-match contributions and associated uncertainties which are likely to be dominated by systematic biases. As long as the uncertainties in such mis-matches are small in absolute terms, even if large in proportional terms, useful crossinformation is possible even with mis-matched spatial partitioning.

\section{Global to regional analyses}

\subsection{Context}

In comparing syntheses of global or regional carbon budgets, an important distinction is whether or not an analysis includes a "residual flux" - the so-called "missing sink".

Figure 3 gives a schematic of two possible situations for combinations of flux estimates. Part (a) shows three joint estimates of two fluxes (notionally land and ocean) with a set of flux values that are consistent with all three estimates. In contrast, part (b) shows three inconsistent estimates with no set of fluxes providing a good fit to all constraints.

There are two complementary ways in which the issue of the residual flux can be formulated in a framework of statistical estimation. One can calculate it explicitly and then test whether it is significantly different from zero, or one can pose the problem from the outset as a hypothesis test, namely that the residual is zero.

Le Quéré et al. (2009) constructed a simple annual budget for atmospheric $\mathrm{CO}_{2}$ over the last $50 \mathrm{yr}$, considering fossil fuel inputs, land-use change, oceanic and terrestrial fluxes, and atmospheric increase. Their interest was largely on long-term changes in this budget, and much of the shortterm variability was driven by the variability in atmospheric growth-rate or modelled terrestrial flux. In this they were implicitly following Bousquet et al. (2000) and subsequent analyses which suggest that terrestrial flux is the dominant driver of interannual variability. Focussing on their uncertainty analyses, Le Quéré et al. (2009) used multi-model ensembles for as many terms in their budget as possible, especially the highly uncertain terrestrial term, but only had single estimates for emissions from land use and fossil carbon. This gives them a very limited ensemble size to estimate distributions but means that systematic effects, such as year-year correlations in model behaviour, are naturally accounted for. They also estimated a residual term based on failure to close their budget and noted that it was generally very large suggesting either missing processes (unlikely at the global scale) or serious inconsistency among their estimates. Sarmiento et al. (2010) have analysed recent decades of the carbon cycle, partitioning land into northern extratropical vs. tropical and southern zones bounded by 18 degree latitudes. For the oceans, 48 degrees south was used for further partitioning into "southern" and "southern hemisphere temperate" oceans. The approach was to estimate a net land flux using the combination of atmospheric $\mathrm{CO}_{2}$ inversions, fossil fuel inventories and ocean carbon modelling. This bypassed the question of whether the land sink is consistent with current models and inventories, and concentrated on the overall temporal behaviour. Their conclusion was that, superimposed on considerable interannual variability, there was a step change from around $0.3 \mathrm{PgC} \mathrm{yr}^{-1}$ terrestrial sink to around $1.15 \mathrm{PgC} \mathrm{yr}^{-1}$ sink from 1989 onwards.

\subsection{Global products}

In this section we apply the principles discussed above to comment briefly on the characterization of uncertainty in the various RECCAP global products.

\subsubsection{Fossil}

Andres et al. (2012) comment on the various types of uncertainty in estimates of fossil fuel emissions. They note that global uncertainty is dominated by uncertainties of the largest emitters, but, fortunately, fractional uncertainty is generally lower for large emitters. Uncertainty is currently increasing as the fraction of emissions from "high uncertainty" countries is growing to become a significant part of the total. Uncertainties increase as we seek more highly resolved estimates in space or time, since the methodology of downscaling estimates by multiplication of national totals by some spatial proxy necessarily convolves uncertainties. There is, as yet, little evidence available for estimating temporal error correlation for fossil fuel emissions, a quantity necessary for efficient trend detection.

There is a separate uncertainty around the use of fossil fuel emissions within inversions since not all combustion immediately yields $\mathrm{CO}_{2}$ (e.g. Enting and Mansbridge, 1991; Folberth et al., 2005; Suntharalingam et al., 2005). This, however, is best treated as an uncertain correction term in the inversion process rather than an uncertainty in the estimation of fossil fuel emissions.

Rayner (2010) generate uncertainty in the parameters of their fossil fuel model using a Monte Carlo technique. Their model calculates emissions at a point as a product of national emissions and a spatial proxy blending nightlights and population. Both the spatial field and national multiplier carry an uncertainty, so the pointwise emissions have a large but uncorrelated component of uncertainty arising from uncertainty in the spatial proxy, plus a smaller component arising from 
uncertainty in national emissions. This second component of uncertainty is correlated at national scales. When emission estimates are aggregated to these national scales, the first component becomes insignificant, and uncertainty is equal to the specified uncertainty in national emissions.

\subsubsection{Land-use change and forestry}

After early speculation of very large emissions from deforestation (Woodwell et al., 1978), Houghton et al. (1983) introduced a "book-keeping" approach that relates carbon stocks to records of land-use change, supplemented by proxy information such as population data.

Houghton (2010) has reviewed various estimates and proposed a range of $\pm 0.5 \mathrm{PgC} \mathrm{yr}^{-1}$. He noted the various contributions to uncertainty as:

- uncertainties about the processes and activities included in the analyses;

- uncertainty about rates of change of land-use change and management;

- uncertainty about density of carbon stocks in affected areas;

- uncertainties regarding the fate of affected ecosystems and carbon stocks.

The question of the fate of the carbon is important. Black carbon comprises a small but increasing component of the budget (Novakov et al., 2003). Similarly, the use of biofuels is a significant part of global combustion (Yevich and Logan, 2003), but the impact on the global-to-regional scale carbon budget depends greatly on whether or not such use is from a sustainable practice that balances emissions with regrowth.

The discussion of the RECCAP global product (Houghton et al., 2012) notes three methods, differing mainly in how the carbon densities are assigned:

- "book-keeping" from agricultural and forestry records this generally has to use representative average carbon densities, but is the only available technique for producing long records;

- remote sensing, which can, in principle, match carbon densities to actual locations where change occurs;

- modelled carbon, but this still requires, as input, a specification of where changes occur.

\subsubsection{Ocean $\mathrm{CO}_{2}$ flux}

The proposed RECCAP ocean $\mathrm{CO}_{2}$ flux product (Rik Wanninkhof, personal communication, 2011) is to be based on the analysis of ocean $\mathrm{CO}_{2}$ partial pressure $\left(p \mathrm{CO}_{2}\right)$.

The air-sea flux is expressed as

$$
F_{\text {sea:air }}=\kappa K_{0} \Delta p \mathrm{CO}_{2}
$$

where $K_{0}$ is the solubility of $\mathrm{CO}_{2}$, and $\kappa$ is a wind-speed dependent transfer coefficient. This is written as

$\kappa=a\left\langle U^{2}\right\rangle^{0.5}$

where $\left\langle U^{2}\right\rangle^{0.5}$ is the mean-square wind speed at $10 \mathrm{~m}$.

The preliminary estimate of annual mean flux is $-1.19 \mathrm{PgC} \mathrm{yr}^{-1}$, with $0.13 \mathrm{PgC} \mathrm{yr}^{-1}$ interannual standard deviation and a decreasing sink trend of $0.1 \mathrm{PgC} \mathrm{yr}^{-1}$ decade $^{-1}$.

The overall uncertainty (expressed as \pm 1 s.d.) in the annual mean flux was estimated at $\pm 0.7 \mathrm{PgC} \mathrm{yr}^{-1}$, attributed to uncertainties of $\pm 0.18 \mathrm{PgC} \mathrm{yr}^{-1}$ from interpolation of the $p \mathrm{CO}_{2}$ data; $\pm 0.42 \mathrm{PgC} \mathrm{yr}^{-1}$ from uncertainty in $\kappa ; \pm 0.28 \mathrm{PgC} \mathrm{yr}^{-1}$ from the $\left\langle U^{2}\right\rangle^{0.5}$ uncertainty; and $\pm 0.5 \mathrm{PgC} \mathrm{yr}^{-1}$ from the correction involved in taking the $p \mathrm{CO}_{2}$ data to a common reference time.

The results are to be presented as maps at $4^{\circ} \times 5^{\circ}$ resolution, for:

- 20-yr mean sea-to-air flux $F_{\text {sea:air }}$ and s.d. of annual means of sea-to-air flux

- trend of sea-to-air flux and error of trend of sea-to-air flux.

For comparison the "T-09" climatology of sea-to-air flux from Takahashi et al. (2009) is specified as sea-to-air flux from T-09 and s.d. of sea-to-air flux.

The various mean data sets are to be supplemented by plots of standard deviations reflecting the seasonal variability and plots reflecting the effect of interannual variability on estimated trends. The various plots of standard deviations are measures of variability, not measures of uncertainty (see discussion in Sect. 3.3 above). However, uncertainties can reflect the amount of variability in cases of incomplete sampling or if we wish to use a climatology to represent a given year.

\subsubsection{Terrestrial carbon modelling}

For terrestrial ecosystems, RECCAP is drawing on several global modelling studies. There is additional modelling for some particular regions. As noted in Sect. 3.2, model intercomparisons can provide a framework for investigation differences between models, but cannot provide quantitative estimates of uncertainties. Huntzinger et al. (2011) propose geostatistical criteria for systematic comparison of terrestrial carbon models.

Section 3.2 notes various studies relevant to specific aspects of calibration uncertainty in terrestrial carbon models (Mitchell et al., 2009; Zaehle et al., 2005; Trudinger et al., 2008; Zhao et al., 2011). Huntzinger et al. (2011) use a geostatistical approach to compare multiple terrestrial models in terms of cross-correlations in order to identify relevant model differences, such as sensitivity to forcing variables. A more 
generic approach to comparing spatially varying data is given by Scipal et al. (2008), who use cross-correlations between three data sets to obtain estimates of the errors of each. This approach is critically dependent on the assumption of no correlation between the errors in the different data sets.

\subsubsection{Inversions}

As soon as we wish to disaggregate the carbon budget into even its coarsest process description (e.g. land vs. ocean uptake), we cannot simply use the global growth rate. We require some ancillary information such as isotopic information (e.g. Francey et al., 1995; Keeling et al., 1995), additional gases (Keeling et al., 1993), or information on spatial gradients (Gurney et al., 2002). This makes even global decompositions from inversions inherently spatial in nature. Uncertainties are characteristically large unless global constraints (e.g. oxygen trends) are available, since the uncertainty will be dominated by the least well-constrained region.

\subsection{Implications for regional budgeting}

Before considering the various regional analyses in RECCAP, we note a comparable (but with less coverage) study. Ciais et al. (2010) compared atmospheric inversions to land-based accounting for the (extra-tropical) Northern Hemisphere. They used inversions for four different models/systems, and compared these results to land-based accounting for four large land regions for which land-based analyses existed. These were:

- SOCCR (CCSP, 2007) for North America;

- CARBO-EUROPE (Schulze et al., 2010);

- IIASA for Russia;

- and Piao et al. (2009) for China.

They concluded that "the NH terrestrial sink estimation is consistent between the top-down and the bottom-up approaches at the scale of the regions considered, given uncertainties associated with each method". The results illustrate the principle of the schematic of Fig. 1, with the top-down estimates having the larger uncertainties for individual regions, while the two approaches show comparable uncertainty on the hemispheric scale due to the negative correlation in the top-down estimates.

The question - where, if anywhere, is there evidence of a missing sink? - can serve as a focus for considering how much the information in the set of regional studies reduces the uncertainty in the global picture. The more general questions are: Do the RECCAP components cross-inform each other? How much do regional studies contribute to a more precise global description? In assessing regional budgets, the uncertainties in fossil carbon emissions play a more important role than on the global scale.
The study by Tans et al. (1990) provided a striking example of using regional information to refine a global description. The $p \mathrm{CO}_{2}$ data for northern and tropical regions were supplemented by an inversion study to determine the northsouth difference in fluxes.

On the other hand, Fig. 4 suggests that reducing the uncertainties in a single region may not translate into more comprehensive constraints. The uncertainties in totals are dominated by the uncertainty in the most poorly known summand.

Our temporal decomposition (see Sect. 4.1) provides a hierarchy of difficulty for synthesising RECCAP components. Difficulties are magnified as we move from estimating most likely values to some measure of uncertainty.

Mean. Specifying some sort of mean flux is the minimum requirement for RECCAP components. Where there may be difficulty in incorporating such results into a global or regional synthesis is when they cannot be referenced to a specific reference time and averaging period.

Rate of change. Many, but not all, of RECCAP means may also have associated rates of change.

Seasonal cycles. Many RECCAP components include estimates of cycles. In particular terrestrial carbon models are usually tuned to reproduce the seasonal cycle. However cycles are not a primary RECCAP focus.

Change of cycles. Estimating longer-term trends on the seasonal cycles should be possible for a number of components, but as with the cycles themselves, this is not a primary focus of RECCAP. However, changes in cycles in response to changing environmental conditions may provide a useful additional constraint on terrestrial models.

Interannual variability. Analysing interannual variability (IAV) poses a challenge for RECCAP. Among the difficulties are: the smaller number of components that include estimates of IAV, the need for consistency in definition of IAV, and the possibility of non-stationarity in the uncertainties (since many aspects of IAV are linked to the phase of the seasonal cycle).

The difficulties for IAV mean that a quantitative answer to the complementary question - when, if ever, is there evidence of a missing sink? - remains elusive.

\section{Concluding remarks}

The RECCAP study (Canadell et al., 2011) is a unique effort in synthesising a large body of quantitative knowledge about the carbon cycle. Experience from comparable exercises in other contexts suggest that as much will be learned about the problems in performing such an exercise for the first time as is learned about the targeted science. Examples from our own experience include:

- Carbon cycle calculations as input to the 1994 IPCC Radiative Forcing Report (Enting et al., 1994) - this was 
already a second attempt, following an unsuccessful attempt organised by the IPCC Technical Services Unit, and even in this second attempt, problems were encountered with ambiguity in classification of fluxes (Enting et al., 1994, appendix A.6);

- The Transcom intercomparison, where initial compromises (e.g. the neglect of reduced carbon, fossil emissions either fixed or with a single global uncertainty) have persisted;

- The OptIC exercise (Trudinger et al., 2008), where a limited focus on the sampling distribution of the estimates has meant a failure to fully address the original aims.

As discussed above, the RECCAP exercise is structured in terms of both global and regional studies. Syntheses can be considered in terms of how regional studies fit into the global perspective. Questions for a regional study are:

- Is it consistent with the global perspective, in particular the global growth of $\mathrm{CO}_{2}$ ?

- Does it refine or modify the global synthesis?

- Do any such modifications of the global synthesis modify other regional estimates?

Each of these questions can only be answered if there is a quantitative understanding of the uncertainties in the respective estimates. This will not be possible in all cases, since in the words of the SOCCR report (CCSP, 2007) noted above, "rarely, even within a sector or discipline, are the statistical pre-requisites of meta-analysis met by the diverse studies of carbon cycle elements".

The RECCAP process also envisages a set of high-level syntheses (Canadell et al., 2011):

Top-down/bottom-up comparisons. This topic is the closest to the present paper. In Sect. 3.5 we noted that the whole process of combining components and propagating uncertainties could, in principle, be done within the inversion process. Ciais et al. (2010) performed a top-down/bottom up comparisons for the four best-studied regions of the globe and found general consistency in the estimates. The questions for RECCAP are whether such consistency is still found when these regional analyses are refined and whether other regions show similar consistency. As noted above, inclusion of uncertainties in fossil carbon emissions will be an essential part of such analyses.

Terrestrial carbon synthesis. The terrestrial biota is the component of the carbon cycle that has:

- greatest spatial heterogeneity;

- greatest interannual variability;

- greatest uncertainty; and

- maybe greatest vulnerability to climate change.
Spatially resolved estimates can come from "data products" as in the study by Jung et al. (2011) or from explicit modelling. The RECCAP analysis draws on several global model studies. Additional terrestrial model studies contribute to some of the regional analyses. Some techniques for assessing the uncertainty, given the difficulties mentioned above, are noted in Sect. 5.2.4.

Interannual variability. As noted in the previous section, characterising the uncertainties in estimates of interannual variability is significantly more difficult than analysing uncertainties in means, trends and cycles. This is an area where more comprehensive analysis is needed.

Attribution. Questions of attribution shift the focus from a descriptive account of fluxes to a mechanistic account of "how is the carbon cycle working?" Many of these issues are captured by Enting (2002, Fig. 14.2), which assigns "functional roles" to the various fluxes. The main roles are "equilibrium" and "perturbation", with "perturbation" subdivided into "forcing", "response" and "random". For current concerns, expanding this to be "forcing", "response", "feedback" and "random" seems more appropriate. This sort of mechanistic view is essentially one of modelling, and so attribution studies from RECCAP and its extensions are likely to reflect this. Attribution studies can, of course, be expected to draw heavily on the techniques developed for attribution of climate change.

Human drivers. Raupach et al. (2007) analysed trends in $\mathrm{CO}_{2}$ emissions for 9 national groupings, using a Kaya identity approach to characterise how the changes over time differed between groups. The additional information from RECCAP may potentially refine such analyses, and the characterisation of uncertainties is important when assessing the significance of any changes in the different patterns of the human drivers.

These four "high-level syntheses" represent four different directions for RECCAP. The "top-down/bottom-up" analysis is a chance to take stock of what has been achieved. "Interannual variability" is a challenge for the future. "Attribution" is a new perspective that will involve shifting the balance between observational and modelling studies. Finally, understanding the role of the human drivers of change in the carbon cycle provides the basis of mitigating such changes. In each of the high-level directions, a comprehensive characterisation of the uncertainties is essential for progress. 


\section{Appendix A}

\section{Notation}

C Covariance matrix for flux estimates - subscripted to denote particular cases.

$F \quad \mathrm{CO}_{2}$ flux to the atmosphere - subscripted to denote particular cases.

G Model operator, mapping fluxes onto a set of observations.

$K_{0} \quad$ Solubility of $\mathrm{CO}_{2}$.

$\mathbf{R}$ Covariance matrix for a set of observations.

$t$ Time.

$U$ Wind-speed, used in converting $p \mathrm{CO}_{2}$ data for fluxes.

W Inverse of covariance matrix for a set of observations.

$\mathbf{X}$ Inverse covariance matrix for flux estimates - subscripted to denote particular cases. Only exists when defined over a linearly independent set of flux components.

$\kappa \quad$ Gas exchange coefficient.

Acknowledgements. The Australian Research Council (ARC) funds the Centre of Excellence for Mathematics and Statistics of Complex Systems (MASCOS). Ian Enting's fellowship at MASCOS was supported in part by CSIRO. Ian Enting also acknowledges hospitality at LSCE during part of the development of this study. Peter Rayner is in receipt of an Australian Professorial Fellowship (DP1096309). P. Ciais received support from the EU-funded COCOS project of the 7th Framework Program for two meetings of preparation of the RECCAP project. Collectively, we express our appreciation to the Transcom community and the RECCAP community.

Edited by: J. Canadell

\section{References}

Andres, R. J., Boden, T. A., Bréon, F.-M., Ciais, P., Davis, S., Erickson, D., Gregg, J. S., Jacobson, A., Marland, G., Miller, J., Oda, T., Olivier, J. G. J., Raupach, M. R., Rayner, P., and Treanton, K.: A synthesis of carbon dioxide emissions from fossil-fuel combustion, Biogeosciences, 9, 1845-1871, doi:10.5194/bg-9-18452012, 2012.

Backus, G. and Gilbert, F.: The resolving power of gross earth data, Geophys. J. R. Astr. Soc., 13, 247-276, 1968.

Beer, C., Reichstein, M., Tomelleri, E., Ciais, P., Jung, M., Carvalhais, N., Rödenbeck, C., Arain, M. A., Baldocchi, D., Bonan, G. B., Bondeau, A., Cescatti, A., Lasslop, G., Lindroth, A., Lomas, M., Luyssaert, S., Margolis, H., Oleson, K. W., Roupsard, O., Veenendaal, E., Viovy, N., Williams, C., Woodward, F. I., and Papale, D.: Terrestrial gross carbon dioxide uptake: Global distribution and covariation with climate, Science, 329, 834-838, doi:10.1126/science.1184984, 2010.

Bousquet, P., Peylin, P., Ciais, P., Le Quéré, C., Friedlingstein, P., and Tans, P. P.: Regional changes in carbon dioxide fluxes of land and oceans since 1980, Science, 290, 1342-1346, 2000.
Canadell, J. G., Ciais, P., Gurney, K., Le Quéré, C., Piao, S., Raupach, M. R., and Sabine, C. L.: An international effort to quantify regional carbon fluxes, EOS, Trans. AGU, 92, 81-82, 2011.

CCSP: The First State of the Carbon Cycle Report (SOCCR): The North American Carbon Budget and Implications for the Global Carbon Cycle. A Report by the U.S. Climate Change Science Program and the Subcommittee on Global Change Research, edited by: King, A. W., Dilling, L., Zimmerman, G. P., Fairman, D. M., Houghton, R. A., Marland, G., Rose, A. Z., and Wilbanks, T. J.: National Oceanic and Atmospheric Administration, National Climatic Data Center, Asheville, NC, USA, 2007.

Chevallier, F., Ciais, P., Conway, T. J., Aalto, T., Anderson, B. E., Bousquet, P., Brunke, E. G., Ciattaglia, L., Esaki, Y., Fröhlich, M., Gomez, A., Gomez-Pelaez, A. J., Haszpra, L., Krummel, P. B., Langenfelds, R. L., Leuenberger, M., Machida, T., Maignan, F., Matsueda, H., Morguí, J. A., Mukai, H., Nakazawa, T., Peylin, P., Ramonet, M., Rivier, L., Sawa, Y., Schmidt, M., Steele, L. P., Vay, S. A., Vermeulen, A. T., Wofsy, S., and Worthy, D.: $\mathrm{CO}_{2}$ surface fluxes at grid point scale estimated from a global 21 year reanalysis of atmospheric measurements. J. Geophys. Res., 115, D21307, doi:10.1029/2010JD013887, 2010.

Ciais, P., Bousquet, P., Freibauer, A., and Naegler, T.: Horizontal displacement of carbon associated with agriculture and its impacts on atmospheric $\mathrm{CO}_{2}$, Global Biogeochem. Cy., 21, GB2014, doi:10.1029/2006GB002741, 2007.

Ciais, P., Borges, A. V., Abril, G., Meybeck, M., Folberth, G., Hauglustaine, D., and Janssens, I. A.: The impact of lateral carbon fluxes on the European carbon balance, Biogeosciences, 5, 1259-1271, doi:10.5194/bg-5-1259-2008, 2008.

Ciais, P., Canadell, J. G., Luyssaert, S., Chevallier, F., Shvidenko, A., Poussi, Z., Jonas, M., Peylin, P., King, A. W., Schulze, E.-D., Piao, S., Rödenbeck, C., Peters, W., and Bréon, F.-M.: Can we reconcile atmospheric estimates of the northern terrestrial carbon sink with land-based accounting?, Current Opinion in Environmental Sustainability, 2, 225-230, doi:10.1016/j.cosust.2010.06.008, 2010.

Cleveland, W. S., Freeny, A. E., and Graedel, T. E.: The seasonal component of atmospheric $\mathrm{CO}_{2}$ : information from new approaches to the decomposition of seasonal time series, J. Geophys. Res., 88C, 10934-10946, 1983.

Committee to Review the IPCC: Climate change assessments: Review of the processes and procedures of the IPCC, Technical report, InterAcademy Council, 2010.

Cramer, W., Kicklighter, D. W., Bondeau, A., Moore, B., Churkina, G., Nemry, B., Ruimy, A. L., Schloss, A., and Participants of the Potsdam NPP model intercomparison: Comparing global models of terrestrial net primary productivity (NPP): overview and key results, Glob. Change Biol., 5, 1-15, 1999.

Cramer, W., Bondeau, A., Woodward, F. I., Prentice, I. C., Betts, R. A., Brovkin, V., Cox, P. M., Fisher, V., Foley, J. A., Friend, A. D., Kucharik, C., Lomas, M. R., Ramankutty, N., Sitch, S., Smith, B., White, A., and Young-Molling, C.: Global response of terrestrial ecosystem structure and function to $\mathrm{CO}_{2}$ and climate change: Results from six dynamic global vegetation models, Glob. Change Biol., 7, 375-373, 2001.

Dee, D. P. and de Silva, A. M.: Maximum-Likelihood Estimation of Forecast and Observation Error Covariance Parameters. Part I: Methodology, Monthly Weather Review, 127, 1822-1834, 1999. 
Doney, S. C., Lindsay, K., Caldeira, K., Campin, J.-M., Drange, H., Dutay, J.-C., Follows, M., Gao, Y., Gnanadesikan, A., Gruber, N., Ishida, A., Joos, F., Madec, G., Maier-Reimer, E., Marshall, J. C., Matear, R. J., Monfray, P., Mouchet, A., Najjar, R., Orr, J. C., Plattner, G.-K., Sarmiento, J., Schlitzer, R., Slater, R., Totterdell, I. J., Weirig, M.-F., Yamanaka, Y., and Yool, A.: Evaluating global ocean carbon models: The importance of realistic physics, Global Biogeochem. Cy., 18, GB3017, doi:10.1029/2003GB002150, 2004.

Enting, I. G.: Inverse Problems in Atmospheric Constituent Transport, CUP, Cambridge, UK, 2002.

Enting, I. G.: Assessing the Information Content in Environmental Modelling: A Carbon Cycle Perspective, Entropy, 10, 556-575; doi: 10.3390/e10040 556, 2008.

Enting, I. G. and Mansbridge,J. V.: Latitudinal distribution of sources and sinks of $\mathrm{CO}_{2}$ : Results of an inversion study, Tellus, 43B, 156-170, 1991.

Enting, I. G., Wigley, T. M. L., and Heimann, M.: Future Emissions and Concentrations of Carbon Dioxide: Key Ocean/Atmosphere/Land Analyses, Tech. rep. 31, CSIRO, Atmos. Res., http://www.cmar.csiro.au/e-print/open/enting/ +2001a0.htm, 1994.

Enting, I. G., Trudinger, C. M., and Francey, R. J.: A synthesis inversion of the concentration and $\delta^{13} \mathrm{C}$ of atmospheric $\mathrm{CO}_{2}$, Tellus, 47B, 35-52, 1995.

Folberth, G., Hauglustaine, D. A., Ciais, P., and Lathiére, J.: On the role of atmospheric chemistry in the global $\mathrm{CO}_{2}$ budget, Geophys. Res. Lett., 32, L08801, doi:10.1029/2004GL021812, 2005.

Francey, R. J., Tans, P. P., Allison, C. E., Enting, I. G., White, J. W. C., and Trolier, M.: Changes in oceanic and terrestrial carbon uptake since 1982, Nature, 373, 326-330, 1995.

Fung, I. Y., John, J., Lerner, J., Matthews, E., Prather, M., Steele, L. P., and Fraser, P. J.: Three-dimensional model synthesis of the global methane cycle, J. Geophys. Res., 96D, 13033-13065, 1991.

Gloor, M., Gruber, N., Sarmiento, J., Sabine, C. L., Feely, R. A., and Rödenbeck, C.: A first estimate of present and preindustrial air-sea $\mathrm{CO}_{2}$ flux patterns based on ocean interior carbon measurements and models, Geophys. Res. Lett., 30, 1010, doi:10.1029/2002GL015594, 2003.

Gourdji, S. M.: Improved estimates of regional-scale landatmosphere $\mathrm{CO}_{2}$ exchange using geostatistical atmospheric inverse models, PhD thesis, U. Michigan, available at: http:// deepblue.lib.umich.edu/handle/2027.42/84599, 2011.

Gurney, K. R., Law, R. M., Denning, A. S., Rayner, P. J., Baker, D., Bousquet, P., Bruhwiler, L., Chen, Y.-H., Ciais, P., Fan, S. M., Fung, I. Y., Gloor, M., Heimann, M., Higuchi, K., John, J., Maki, T., Maksyutov, S., Masarie, K., Peylin, P., Prather, M., Pak, B. C., Randerson, J., Sarmiento, J., Taguchi, S., Takahashi, T., and Yuen, C. W.: Towards robust regional estimates of $\mathrm{CO}_{2}$ sources and sinks using atmospheric transport models, Nature, 415, 626-630, 2002.

Ha-Duong, M., Swart, R., Petersen, A., and Bernstein, L.: Uncertainty management in the IPCC: Agreeing to disagree. Global Environmental Change, 17, 8-11, 2007.

Heimann, M., Rödenbeck, C., and Gloor, M.: Spatial and temporal distribution of sources and sinks of carbon dioxide, in: The Global Carbon Cycle: Integrating Humans, Climate and the Natural World, edited by: Field, C. B. and Raupach, M. R., chapter 8 ,
187-204, Island Press, Washington DC, 2004.

Houghton, R. A.: How well do we know the flux of $\mathrm{CO}_{2}$ from landuse change?, Tellus, 62B, 337-351, 2010.

Houghton, R. A., Hobbie, J. E., Melillo, J. M., Moore, B., Peterson, B. J., Shaver, G. M., and Woodwell, G. M.: Changes in the carbon content of terrestrial biota and soils between 1860 and 1980: a net release of $\mathrm{CO}_{2}$ to the atmosphere, Ecol. Monogr., 53, 235-262, 1983.

Houghton, R. A., van der Werf, G. R., DeFries, R. S., Hansen, M. C., House, J. I., Le Quéré, C., Pongratz, J., and Ramankutty, N.: Chapter G2 Carbon emissions from land use and land-cover change, Biogeosciences Discuss., 9, 835-878, doi:10.5194/bgd9-835-2012, 2012.

Huntzinger, D. N., Gourdji, S. M., Mueller, K. L., and Michalak, A. M.: A systematic approach for comparing modeled biospheric carbon fluxes across regional scales, Biogeosciences, 8, 15791593, doi:10.5194/bg-8-1579-2011, 2011.

Jacobson, A. R., Mikaloff Fletcher, S. E., Gruber, N., Sarmiento, J. L., and Gloor, M.: A joint atmosphere-ocean inversion for surface fluxes of carbon dioxide: 1. methods and global-scale fluxes. Global Biogeochem. Cy., 21, GB1019, doi:10.1029/2005GB002556, 2007a.

Jacobson, A. R., Mikaloff Fletcher, S. E., Gruber, N., Sarmiento, J. L., and Gloor, M.: A joint atmosphere-ocean inversion for surface fluxes of carbon dioxide: 2. regional results, Global Biogeochem. Cy., 21, GB1020, doi:10.1029/2006GB002703, 2007b.

Jung, M., Vetter, M., Herold, M., Churkina, G., Reichstein, M., Zaehle, S., Ciais, P., Viovy, N., Bondeau, A., Chen, Y., Trusilova, K., Feser, F., and Heimann, M.: Uncertainties of modeling gross primary productivity over Europe: A systematic study on the effects of using different drivers and terrestrial biosphere models, Global Biogeochem. Cy., 21, GB4021, doi:10.1029/2006GB002915, 2007.

Jung, M., Reichstein, M., and Bondeau, A.: Towards global empirical upscaling of FLUXNET eddy covariance observations: validation of a model tree ensemble approach using a biosphere model, Biogeosciences, 6, 2001-2013, doi:10.5194/bg-6-20012009, 2009.

Jung, M., Reichstein, M., Margolis, H. A., Cescatti, A., Richardson, A. D., Arain, M. A., Arneth, A., Bernhofer, C., Bonal, D., Chen, J., Gianelle, D., Gobron, N., Kiely, G., Kutsch, W., Lasslop, G., Law, B. E., Lindroth, A., Merbold, L., Montagnani, L., Moors, E. J., Papale, D., Sottocornola, M., Vaccari, F., and Williams, C.: Global patterns of land-atmosphere fluxes of carbon dioxide, latent heat, and sensible heat derived from eddy covariance, satellite, and meteorological observations, J. Geophys. Res., 116, G00J07, doi:10.1029/2010JG001566, 2011.

Kaminski, T., Rayner, P. J., Heimann, M., and Enting, I. G.: On aggregation errors in atmospheric transport inversions, J. Geophys. Res., 106, 4703-4715, 2001.

Keeling, C. D., Whorf, T. P., Wahlen, M., and van der Plicht, J.: Interannual extremes in the rate of rise of atmospheric carbon dioxide since 1980, Nature, 375, 666-670, 1995.

Keeling, R. F., Najjar, R. P., Bender, M. L., and Tans, P. P.: What atmospheric oxygen measurements can tell us about the global carbon cycle, Global Biogeochem. Cy., 7, 37-67, 1993.

Knutti, R., Abramowitz, G., Collins, M., Eyring, V., Gleckler, P. J., Hewitson, B., and Mearns, L.: Good Practice Guidance 
paper on Assessing and Combining Model Climate Projections, IPCC Working Group I Technical Support Unit, University of Bern, Bern, Switzerland, 2010.

Lauvaux, T., Pannekoucke, O., Sarrat, C., Chevallier, F., Ciais, P., Noilhan, J., and Rayner, P. J.: Structure of the transport uncertainty in mesoscale inversions of $\mathrm{CO}_{2}$ sources and sinks using ensemble model simulations, Biogeosciences, 6, 1089-1102, 2009 ,

http://www.biogeosciences.net/6/1089/2009/.

Le Quéré, C., Raupach, M. R., Canadell, J. G. , Marland, G., Bopp, L., Ciais, P., Conway, T. J., Doney, S. C., Feely, R. A., Foster, P., Friedlingstein, P., Gurney, K., Houghton, R. A., House, J. I., Huntingford C., Levy, P. E., Lomas, M. R., Majkut, J., Metzl, N., Ometto, J. P., Peters, G. P., Prentice, I. C., Randerson, J. T., Running, S. W., Sarmiento, J. L., Schuster, U., Sitch S., Takahashi, T., Viovy, N., van der Werf, G. R., and Woodward, F. I.: Trends in the sources and sinks of carbon dioxide, Nat. Geosci., 2, 831-836, 2009.

Michalak, A., Bruhwiler, L., and Tans, P.: A geostatistical approach to surface flux estimation of atmospheric trace gases, J. Geophys. Res., 109, D14109, doi:10.1029/2003JD004422, 2004.

Michalak, A., Hirsch, A., Bruhwiler, L., Gurney, K. R., Peters, W., and Tans, P. P.: Maximum likelihood estimation of covariance parameters for Bayesian atmospheric trace gas surface flux inversions, J. Geophys. Res., 110, D24107, doi:10.1029/2005/JD005970, 2005.

Mitchell, S., Beven, K., and Freerd, J.: Multiple sources of predictive uncertainty in modeled estimates of net ecosystem $\mathrm{CO}_{2}$ exchange, Ecol. Modell., 220, 3259-3270, 2009.

Novakov, T., Ramanathan, V., Hansen, J. E., Kirchstetter, T. W., Sato, M., Sinton, J. E., and Sathaye, J. A.: Large historical changes of fossil-fuel black carbon aerosols, Geophys. Res. Lett., 30, 1324, doi:10.1029/2002GL016345, 2003.

Orr, J. C., Maier-Reimer, E., Mikolajewicz, U., Monfray, P., Sarmiento, J. L., Toggweiler, J. R., Taylor, N. K., Palmer, J., Gruber, N., Sabine, C. L., Le Quéré, C., Key, R. M., and Boutin, J.: Estimates of anthropogenic carbon uptake from four threedimensional global ocean models, Global Biogeochem. Cy., 15, 43-60, doi:10.1029/2000GB001273, 2001.

Piao, S. L., Fang, J. Y., Ciais, P., Peylin, P., Huang, Y., Sitch, S., and Wang, T.: The carbon balance of terrestrial ecosystems in China, Nature, 458, 1009-1082, 2009.

Raupach, M. R., Rayner, P. J., Barrett, D. J., DeFries, R. S., Heimann, M., Ojima, D. S., Quegan, S., and Schmullius, C. C.: Model-data synthesis in terrestrial carbon observation: methods, data requirements and data uncertainty specifications. Glob. Change Biol., 11, 378-397 doi: 10.1111/j.13652486.2005.00917.x, 2005.

Raupach, M. R., Marland, G., Ciais, P., Le Quéré, C., Canadell, J. G., and Klepper, G.: Global and regional drivers of accelerating $\mathrm{CO}_{2}$ emissions, P. Natl. Acad. Sci., 104, 10288-10293, 2007.

Rayner, P. J.: The current state of carbon-cycle data assimilation. Current Opinion in Environmental Sustainability, 2, 289-296, doi:10.1016/j.cosust.2010.05.005, 2010.

Sarmiento, J. L. and Sundquist, E. T.: Revised budget for the oceanic uptake of anthropogenic carbon dioxide, Nature, 356, 589-593, 1992.

Sarmiento, J. L., Gloor, M., Gruber, N., Beaulieu, C., Jacobson, A. R., Mikaloff Fletcher, S. E., Pacala, S., and Rodgers, K.: Trends and regional distributions of land and ocean carbon sinks, Biogeosciences, 7, 2351-2367, doi:10.5194/bg-7-2351-2010, 2010.

Schulze, E.-D., Ciais, P., Luyssaert, S., Schrumpf, M., Janssens, I. A., Thiruchittampalam, B., Theloke, J., Saurat, M., Bringezu, S., Lelieveld, J., Lohila, A., Rebmann, C., Jung, M., Bastviken, D., Abril, G., Grassi, G., Leip, A., Freibauer, A., Kutsch, W., Don, A., Nieschulze, J., Börner, A., Gash, J. H., and Dolman, A. J.: The European carbon balance. part 4: integration of carbon and other trace-gas fluxes, Glob. Change Biol., 16, 1451-1469, doi:10.1111/j.1365-2486.2010.02215.x, 2010.

Scipal, K., Holmes, T., de Jeu, R., Naeimi, V., and Wagner, W.: A possible solution for the problem of estimating the error structure of global soil moisture data sets, Geophys. Res. Lett., 35, L24403, doi:10.1029/2008GL035599, 2008.

Sitch, S., Huntingford, C., Gedney, N., Levy, P. E., Lomas, M., Piao, S. L., Betts, R., Ciais, P., Cox, P., Friedlingstein, P., Jones, C. D., Prentice, I. C., and Woodward,F. I.: Evaluation of the terrestrial carbon cycle, future plant geography and climatecarbon cycle feedbacks using five Dynamic Global Vegetation Models (DGVMs), Glob. Change Biol., 14, 2015-2039, doi:10.1111/j.1365-2486.2008.01626.x, 2008.

Stephens, B. B., Gurney, K. R., Tans, P. P., Sweeney,C., Peters, W., Bruhwiler, L., Ciais, P., Ramonet, M., Bousquet, P., Nakazawa, T., Aoki, S., Machida, T., Inoue, G., Vinnichenko, N., Lloyd, J., Jordan, A., Heimann, M., Shibistova, O., Langenfelds, R. L., Steele, L. P., Francey, R. J., and Denning, A. S.: Weak northern and strong tropical land carbon uptake from vertical profiles of atmospheric $\mathrm{CO}_{2}$, Science, 316, 1732-1735, doi:10.1126/science.1137004, 2007.

Suntharalingam, P., Randerson, J. T., Krakaeur, N., Jacob, D. J., and Logan, J. A.: Influence of reduced carbon emissions and oxidation on the distribution of atmospheric $\mathrm{CO}_{2}$ : Implications for inversion analyses, Global Biogeochem. Cy., 19, GB4003, doi:10.1029/2005GB002493, 2005.

Takahashi, T., Sutherland, S. C., Wanninkhof, R., Sweeney, C., Feely, R. A., Chipman, D. W., Hales, B., Friederich, G., Chavez, F., Sabine, C., Watson, A., Bakker, D. C. E., Schuster, U., Metzl, N., Yoshikawa-Inoue, H., Ishii, M., Midorikawa, T., Nojiri, Y., Körtzinger, A., Steinhoff, T., Hoppema, M., Olafsson, J., Arnarson, T. S., Tilbrook, B., Johannessen, T., Olsen, A., Bellerby, R., Wong, C. S., Delilles, B., Bates, N. R., and de Baar, H. J. W.: Climatological mean and decadal change in surface ocean $p \mathrm{CO}_{2}$, and net sea-air $\mathrm{CO}_{2}$ flux over the global oceans. Deep-Sea Res. Pt. II, 56, 554-557, doi:10.1016/j.dsr2.2008.12.009, 2009.

Tans, P. P., Fung, I. Y., and Takahashi, T.: Observational constraints on the global atmospheric $\mathrm{CO}_{2}$ budget, Science, 247, 14311438, 1990.

Tarantola, A.: Inverse Problem Theory: Methods for Data Fitting and Model Parameter Estimation, SIAM, Philadelphia, 2005.

Thompson, D. W. J., Wallace, J. M., Kennedy, J. J., and Jones, P. D.: An abrupt drop in Northern Hemisphere sea surface temperature around 1970, Nature, 467, 444-447, doi:10.1038/nature09394, 2010.

Trampert, J. and Sneider, R.: Model estimation biased by truncated expansions: Possible artifacts in seismic tomography, Science, 271, 1257-1260, 1996.

Trudinger, C. M., Raupach, M. R., Rayner, P. J., Kattge, J., Liu, Q., Pak, B. C., Reichstein, M., Renzullo, L., Richardson, A. D., 
Roxburgh, S. H., Styles, J., Wang, Y. P., Briggs, P. R., Barrett, D., and Nikolova, S.: OptIC project: an intercomparison of optimization techniques for parameter estimation in terrestrial biogeochemical models, J. Geophys. Res., 112, G02027, doi:10.1029/2006/JG000367, 2008.

van der Werf, G. R., Randerson, J. T., Giglio, L., Collatz, G. J., Kasibhatla, P. S., and Arellano Jr., A. F.: Interannual variability of global biomass burning emissions from 1997 to 2004, Atmos. Chem. Phys. Discuss., 6, 3175-3226, doi:10.5194/acpd-6-31752006, 2006.

Wang, Y.-P., Trudinger, C. M., and Enting, I. G.: A review of applications of model-data fusion to studies of terrestrial carbon fluxes at different scales, Agricultural and Forest Meteorology, 149, 1829-1842, 2009.

Wolf, A., Berry, J. A., and Asner, G. P.: Allometric constraints on sources of variability in multi-angle reflectance measurements, Remote Sens. Environ., 114, 1205-1219, doi:10.1016/j.rse.2010.01.013, 2010.

Woodwell, G. M., Whittaker, R. H., Reiners, W. A., Likens, G. E., Delwiche, C. C., and Botkin, D. B.: The biota and the world carbon budget, Science, 199, 141-146, 1978.
Wunsch, C. and Minster, J.-F.: Methods for box models and ocean circulation tracers: Mathematical programming and non-linear inverse theory, J. Geophys. Res., 87C, 5647-5662, 1982.

Yevich, R. and Logan, J. A.: An assessment of biofuel use and burning of agricultural waste in the developing world, Global Biogeochem. Cy., 17, 1095, doi:10.1029/2002GB001952, 2003.

Zaehle, S., Sitch, S., Smith, B., and Hatterman, F.: Effects of parameter uncertainties on the modeling of terrestrial biosphere dynamics, Global Biogeochem. Cy., 19, GB3020, doi:10.1029/2004GB002395, 2005.

Zhao, Y., Ciais, P., Peylin, P., Viovy, N., Longdoz, B., Bonnefond, J. M., Rambal, S., Klumpp, K., Olioso, A., Cellier, P., Maignan, F., Eglin, T., and Calvet, J. C.: How errors on meteorological variables impact simulated ecosystem fluxes: a case study for six French sites, Biogeosciences Discuss., 8, 2467-2522, doi:10.5194/bgd-8-2467-2011, 2011.

Zupanski, D., Denning, A. S., Uliasz, M., Zupanski, M., Schuh, A. E., Rayner, P. J., Peters, W., and Corbin, K. D.: Carbon flux bias estimation employing maximum likelihood ensemble filter (MLEF), J. Geophys. Res., 112, D17107, doi:10.1029/2006JD008371, 2007. 